\title{
The role of microwave ablation in management of functioning pancreatic neuroendocrine tumors
}

\author{
Alexey Victorovich Egorov ${ }^{1}$, Ivan Alekseevich Vasilyev ${ }^{1}$, Gaziyav Hadisovich Musayev ${ }^{2}$, \\ Anna Victorovna Mironova ${ }^{3}$ \\ ${ }^{1}$ Abdominal Surgery Department, ${ }^{2}$ General Surgery, ${ }^{3}$ Faculty Surgery, University Clinical Hospital №1 of Sechenov First Moscow State Medical \\ University, Moscow, Russian Federation \\ Contributions: (I) Conception and design: AV Egorov, IA Vasilyev, GH Musaev; (II) Administrative support: AV Egorov, IA Vasilyev; (III) Provision \\ of study materials or patients: All authors; (IV) Collection and assembly of data: All authors; (V) Data analysis and interpretation: All authors; (VI) \\ Manuscript writing: All authors; (VII) Final approval of manuscript: All authors. \\ Correspondence to: Ivan Alekseevich Vasilyev, MD, PhD. 6, Bolshaya Pirogovskaya str., Moscow, 119435, Russian Federation. Email: Vvc@list.ru.
}

\begin{abstract}
Background: Surgical resection is considered to be the only potentially curative option for patients with pancreatic neuroendocrine tumors (pNETs). High risk rates of perioperative complications make minimally invasive ablative techniques a novel perspective and alternative treatment option for pancreatic neuroendocrine tumors. This study aims to present the first experience of using a microwave ablation in management of pNETs.

Methods: Sechenov University has an experience of treating more than 400 patients with hormoneproducing tumors of the pancreas, 7 of which were treated by microwave ablation (MWA).

Results: In all patients that underwent MWA, a regression of hormonal symptomatic was achieved. Two patients required readmission a month later for draining of pseudocyst and abscess.

Conclusions: The exact role of microwave ablation in the treatment of non-metastatic pancreatic neuroendocrine tumors has not been defined yet. There is a lack of large prospective randomized studies and the reason for this is that local tumor destruction is indicated in selected cases only, thus making it difficult to analyze a large group of patients and assess long-term results of the treatment. However, microwave ablation allows to take a better control of symptoms in patients with hormone overproduction and in those with high risk of postoperative complications.
\end{abstract}

Keywords: Insulinoma; minimally invasive surgery; ablative techniques

Submitted Jul 01, 2019. Accepted for publication Nov 29, 2019.

doi: 10.21037 /gs.2019.12.07

View this article at: http://dx.doi.org/10.21037/gs.2019.12.07

\section{Introduction}

Surgical resection is considered to be the only potentially curative option for patients with pancreatic neuroendocrine tumors. Frequency of surgery complications varies from $33 \%$ to $52 \%$, while pancreatic fistulas occur in $8-19 \%$ of cases (1-5). Therefore, it is necessary to search for alternative methods of treatment in order to achieve better outcomes. In recent literature, single cases of local ablative techniques with different modalities have been described including ethanol ablation, radiofrequency ablation
(RFA) and microwave ablation (MWA). However, definite indications for such treatment options as an alternative to conventional surgery have not been defined yet. In most cases ablation is applied in patients with poor performance status or in cases of metastatic functional neuroendocrine tumors in order to manage hormonal syndrome. We present our experience of microwave ablation technique for hormonally active pancreatic tumors as a novel organsparing and minimally invasive method of treatment. 
Table 1 Patients characteristics

\begin{tabular}{|c|c|c|c|c|c|c|c|}
\hline No. & Sex & Age & Reason for the choice of MWA & Location & Size, $\mathrm{mm}^{2}$ & Ki 67 index, \% & Grade \\
\hline 1 & M & 81 & Poor somatic state & Head & $21 \times 10$ & 4 & 2 \\
\hline 2 & $\mathrm{~F}$ & 87 & Poor somatic state & Head & $12 \times 10$ & 2 & 1 \\
\hline 3 & $\mathrm{~F}$ & 75 & Poor somatic state & Head & $16 \times 14$ & $1-2$ & 1 \\
\hline 4 & $\mathrm{~F}$ & 78 & Poor somatic state & Head-body & $22 \times 17$ & $1-2$ & 1 \\
\hline 5 & M & 37 & Alternative to Whipple procedure on "soft" pancreas & Head & $19 \times 15$ & $3-5$ & 2 \\
\hline 6 & $\mathrm{~F}$ & 46 & Alternative to Whipple procedure on "soft" pancreas & Head & $15 \times 14$ & ND & ND \\
\hline 7 & $\mathrm{~F}$ & 55 & Alternative to total duodenopancreatectomy in MEN-1 & Head & $17 \times 11$ & $1-2$ & 1 \\
\hline
\end{tabular}

MWA, microwave ablation; ND, not done.

\section{Methods}

The principle of microwave ablation is cell death via coagulation necrosis. Electromagnetic waves produce the agitation of water molecules and induce frictional heating of the tumor tissue. This method is similar to radiofrequency ablation, however, MWA offers more benefits and has several other advantages. The effect of MWA does not depend on tissue impedance, it does not have electrical circuit, does not require cooling. MWA has less susceptibility to heat-sinks as a result of the shorter wavelength comparing with RFA. More effective transfer of the microwave energy to the biological tissues reduces heating time, affecting the necessary zone by high temperature. Water vaporization and charring do not limit ablation area as it is with RFA due to electrical insulation. As a result, the microwave field penetrates the tissue deeper. This feature also significantly reduces the time of ablation (6-8).

Sechenov University has an experience of treating more than 400 patients with hormone-producing tumors of the pancreas, seven of which underwent microwave ablation (Table 1). MWA was applied in the following categories of patients:

(I) Senior patients with poor performance status diagnosed with pancreatic head insulinomas accompanied by severe hypoglycemia. Patients No. 1-4 mean age 80 years (range, $75-87$ years) manifesting with weekly episodes of hypoglycemic comas were not candidates for traditional surgery.

(II) Young patients diagnosed with well-differentiated pancreatic head insulinomas G1-G2 (according to WHO 2019 classification) with high risk of postoperative complications due to functionally active pancreas. We performed MWA for patients
No. 5-6 as an alternative to Whipple procedure.

(III) Patients with multiple endocrine neoplasia type 1 and multiple pancreatic tumors. Patient No. 7 had distal pancreatectomy due to pNETs of body and tail before and refused of total excision of pancreatic head remnant.

The pretreatment workup included complete clinical history and physical examination, fasting test, imaging techniques (CT, EUS) and routine preoperative studies. Core needle biopsy for pathology report was performed before MWA.

Indications for MWA for patients No. 1-4 were tumor location in the pancreatic head and high risk of intra- and postoperative complications due to severe general somatic state. US-guided percutaneous MWA was performed in patient No. 1.

Patient No. 2 already had enucleation of pancreatic insulinoma located in the head 8 years ago. Afterwards another insulinoma appeared in pancreatic head, minilaparotomy approach for MWA was used in order to provide safe access to the pancreatic head. MWA approaches for patient No. 3 and No. 4 were laparotomy and laparoscopy respectively.

Patients No. 5 and No. 6 were relatively young, and both had neuroendocrine tumors deeply in the tissue of pancreatic head close to the main duct. Therefore, tumor enucleation could not be performed, and MWA was chosen as a treatment option.

Patient No. 7 had two MEN-1 associated neuroendocrine tumors located deeply in the head of pancreatic tissue. This patient underwent a distal pancreatectomy due to malignant PP-oma 3 years before. Taking into account the localization of the tumors surgical excision meant total pancreatectomy. Patient refused to undergo total pancreatectomy, thus as an 

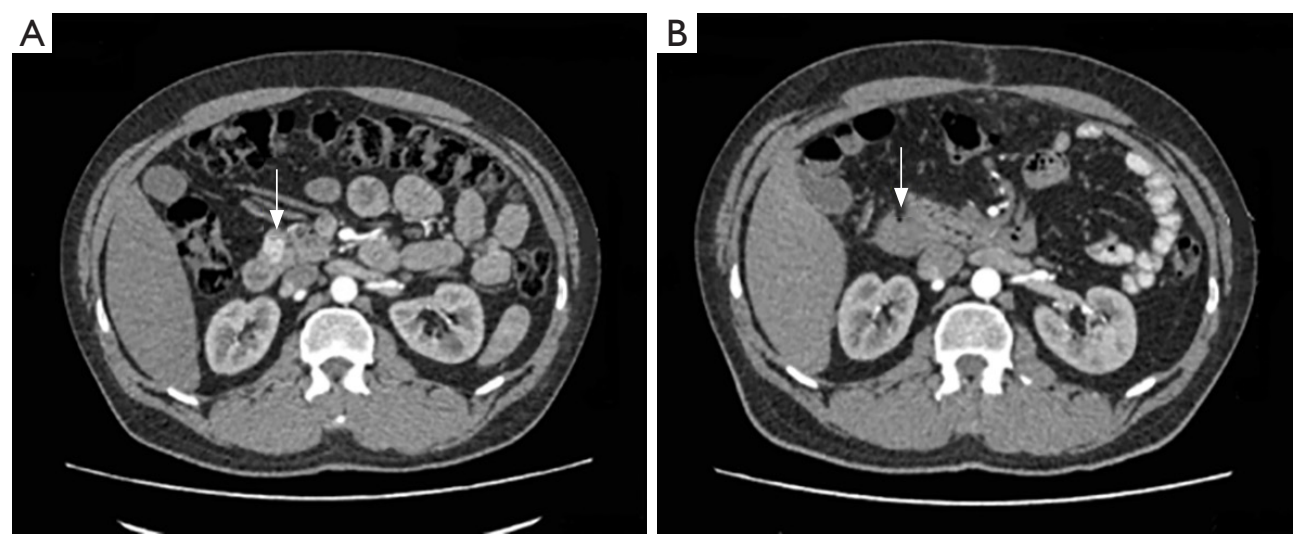

Figure 1 Patient No. 5, pancreatic head insulinoma before treatment and 2 months after microwave ablation (MWA). Tumor area is indicated by the arrow.

Table 2 Microwave ablation (MWA) results

\begin{tabular}{lcccc}
\hline Patient & Age & Clinical effect & Complications & Observation time, months \\
\hline No. 1 & 81 & + & + & $2^{\dagger}$ \\
No. 2 & 87 & + & Pseudocyst of pancreatic head & 42 \\
No. 3 & 75 & + & - & 11 \\
No. 4 & 78 & + & Pseudocyst of pancreatic head & 36 \\
No. 5 & 37 & + & + & 38 \\
No. 6 & 46 & 55 & + & 33 \\
No. 7 & & + & & 38 \\
\hline
\end{tabular}

${ }^{\dagger}$, patient No. 1 died 2 months later due to myocardial infarction.

alternative to aggressive surgery we suggested MWA to be performed.

\section{Results}

Clinical presentation of organic hyperinsulinism in all patients who underwent MWA regressed during the first 3 days, subsequently all of them were normoglycaemic. The average patient observation time is 31 months $(\mathrm{min}=$ 11, $\max =42$ ). Patient No. 1 died 2 months later due to myocardial infarction. Other patients are alive and asymptomatic without any evidence of tumor recurrence. Imaging studies show tumor replacement with inflammatory infiltrate and its transformation to the fibrosis (Figure 1). Table 2 shows clinical outcomes after microwave ablation.

In the postoperative period, two patients had pseudocysts in the ablation zone. Both of them were asymptomatic. Patient No. 6 had a pseudocyst $4 \mathrm{~cm}$ in diameter, which shrunk progressively and disappeared 2 years later without any treatment (Figure 2).

Another pseudocyst was detected on imaging 10 months after MWA in Patient No. 3. Because of its large size $(8 \mathrm{~cm}$ in diameter), we managed it with minimally invasive technique. Patient No.7 was diagnosed with postoperative pancreatic fistula grade B 1 month after MWA was performed. We managed it successfully with US-guided percutaneous drainage.

\section{Discussion}

Pancreatic neuroendocrine tumors represent 1-2\% of all pancreatic lesions. Major part of pNETs are welldifferentiated tumors grade 1 or 2 according to the WHO classification. Insulinomas are the most common functioning NETs, $80 \%$ of which are up to $1.5 \mathrm{~cm}$ $(9,10)$. Surgical resection is considered to be the only 

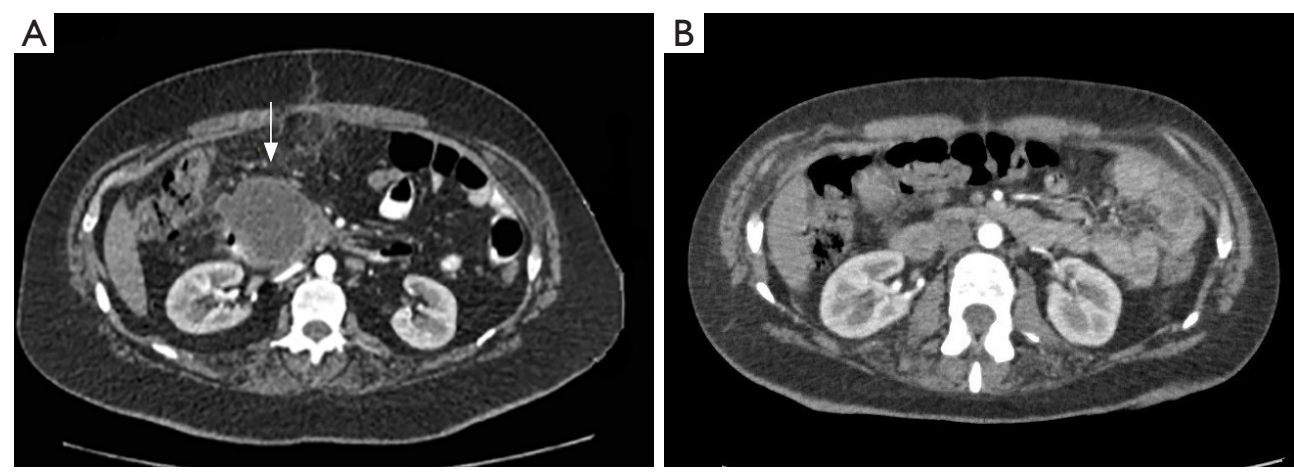

Figure 2 CT of Patient No. 6, pseudocyst in the ablation area 1 and 24 months after microwave ablation (MWA). Pseudocyst is indicated by the arrow.

potentially curative option for patients with pancreatic neuroendocrine tumors and because of its some limitations and postoperative-related complications, there is a profound interest in finding and developing better and more effective methods of treatment.

In our literature review, we have found that there are only few publications focusing on methods of local destruction as a potential alternative to conventional surgical treatment of insulin-producing NETs (Table 3).

Among 43 described patients, ethanol ablation was applied to 31, RFA to 11 and MWA was used in one patient. Whereas a complete reduction of hypoglycemic symptoms was achieved in 38 patients, a reduction of frequency of the attacks was made in three patients and only one patient did not show any beneficial result. In two cases, recurrent interventions were needed in order to achieve stable clinical results. Complications grade 3-4 by Clavien-Dindo classification occurred in three patients after ethanol ablation, two of whom had pseudocyst and one had intraoperative bleeding. Indications for local destruction methods of pancreatic insulinomas, described by the authors, absolutely fit our conception of MWA use in the following situations:

(I) severe general somatic state of the patient, which does not allow the traditional surgical interventions to be performed;

(II) patient refuses to undergo surgery;

(III) high risk of intra- and postoperative complications;

(IV) applying ablation techniques for pancreatic head lesions as an organ-sparing alternative to Whipple procedure and total pancreatectomy.

In addition, among the large number of local ablative techniques used for liver metastasis, the most frequent one is microwave ablation since it has numerous advantages.
The advantages are the following: short time required for the procedure compared to RFA, an average 10 minutes against 40 with RFA; less effect of blood vessels heat remove; simpler technical design that does not require a cooling circuit; lower cost compared to RFA; wider active heating zone, higher temperatures in the target zone for shorter processing times and no heat sink effect $(7,36)$.

There have been only two publications reported in the literature, describing the use of microwave ablation in cases with insulinomas. Chen and co-authors resorted to MWA to stop hypoglycemia in a patient with comorbidities, as in such case it is a contraindication for surgery (24). A group of authors from Chicago performed MWA of a liver metastases of a malignant insulinoma to control hypoglycemia (37).

Our experience has demonstrated a complete control of hypoglycemia in all patients after MWA of pancreatic head insulinomas. This tumor localization is the most difficult and challenging one for surgical excision. In the case when the tumor was close to duodenum or pancreatic duct, ablation was performed from several points to reduce the risk of damage. We had 2 complications grade IIIa (ClavienDindo) and the rest 5 patients did not require any specific treatment in the postoperative period. None presented neither with tumor recurrence nor hypoglycemic syndrome.

\section{Conclusions}

The role of local destruction methods in the treatment of non-metastatic neuroendocrine tumors of pancreas has not been defined yet. There is no doubt that surgery still plays a main role in the treatment of this group of patients. Application of alternative methods can be done in single cases only with strict indications, thus making 
Table 3 Literature data on insulinomas local destruction methods

\begin{tabular}{|c|c|c|c|c|}
\hline Author & Year & No. of cases & Treatment method & Reason of refusal of conventional surgical intervention \\
\hline C. Jurgensen (12) & 2006 & 1 & Ethanol ablation under EUS control & Severe somatic state \\
\hline P. H. Deprez (13) & 2008 & 1 & Ethanol ablation & Severe somatic state \\
\hline S. Limmer (14) & 2009 & 1 & RFA & Severe somatic state \\
\hline F. P. Vleggaar (16) & 2011 & 1 & Ethanol ablation & Risk of intraoperative complications \\
\hline M. J. Levy (17) & 2012 & 8 & Ethanol ablation & Whipple procedure/severe somatic state \\
\hline C. Schnack (18) & 2012 & 1 & Ethanol ablation under EUS control & Severe somatic state \\
\hline V. Procházka (19) & 2012 & 1 & RFA & Severe somatic state \\
\hline S. Rossi (22) & 2014 & 2 & RFA & Severe somatic state/refuse of surgery \\
\hline S. Y. Qin (23) & 2014 & 4 & Ethanol ablation under EUS control & Patient refuse of surgery \\
\hline O. T. Chen (24) & 2015 & 1 & MWA & Severe somatic state: lung cancer stage 4 \\
\hline S. Lakhtakia (25) & 2016 & 3 & RFA & Severe somatic state \\
\hline D. Yang (26) & 2015 & 4 & Ethanol ablation under EUS control & Severe somatic state/refuse of surgery \\
\hline W. H. Paik (27) & 2016 & 3 & Ethanol ablation under EUS control & $\begin{array}{l}\text { Severe somatic state/pancreas resection in medical } \\
\text { history }\end{array}$ \\
\hline $\begin{array}{l}\text { G. Trikudanathan } \\
\text { (28) }\end{array}$ & 2016 & 1 & Ethanol ablation under EUS control & Severe somatic state \\
\hline Y. Luo (33) & 2017 & 1 & Ethanol ablation under EUS control & Distal pancreatectomy in medical history with no effect \\
\hline M. Mittal (34) & 2017 & 1 & Ethanol ablation under EUS control & Severe somatic state \\
\hline $\begin{array}{l}\text { A. de Sousa Lages } \\
\text { (35) }\end{array}$ & 2017 & 1 & Ethanol ablation under EUS control & Severe somatic state \\
\hline
\end{tabular}

it difficult to analyze a large group of patients and assess long-term results of the treatment. Nevertheless, MWA gives the opportunity for effective control of symptoms of hormonal hyperproduction in patients with high and extremely high risk of postoperative complications. Definite conclusions of clinical efficiency of MWA in the treatment of neuroendocrine tumors can be only made after analyzing the long-term results and further accumulating a profound clinical experience.

\section{Acknowledgments}

None.

\section{Footnote}

Conflicts of Interest: The authors have no conflicts of interest to declare. 
Ethical Statement: The authors are accountable for all aspects of the work in ensuring that questions related to the accuracy or integrity of any part of the work are appropriately investigated and resolved. Written informed consent was obtained from the patients for publication of this manuscript and any accompanying images.

\section{References}

1. Crippa S, Zerbi A, Boninsegna L, et al. Surgical management of insulinomas: short- and long-term outcomes after enucleations and pancreatic resections. Arch Surg 2012;147:261-6.

2. de Santibañes M, Cristiano A, Mazza O, et al. Endogenous hyperinsulinemic hypoglycemia syndrome: surgical treatment. Cir Esp 2014;92:547-52.

3. Egorov AV, Musaev G, Kondrashin SA, et al. Prognostic factors of the immediate results of surgical treatment of organic hyperinsulinism. Khirurgiia (Mosk) 2011;(6):60-5.

4. Tsang YP, Lang BH, Shek TW. Assessing the short- and long-term outcomes after resection of benign insulinoma. ANZ J Surg 2016;86:706-10.

5. Varma V, Tariciotti L, Coldham C, et al. Preoperative localisation and surgical management of insulinoma: single centre experience. Dig Surg 2011;28:63-73.

6. Carrafiello G, Lagana D, Mangini M, et al. Microwave tumors ablation: principles, clinical applications and review of preliminary experiences. Int J Surg 2008;6 Suppl 1:S65-9.

7. Martin RC, Scoggins CR, McMasters KM. Safety and efficacy of microwave ablation of hepatic tumors: a prospective review of a 5-year experience. Ann Surg Oncol 2010;17:171-8.

8. Simon CJ, Dupuy DE, Mayo-Smith WW. Microwave ablation: principles and applications. Radiographics 2005;25 Suppl 1:S69-83.

9. Chiruvella A, Kooby DA. Surgical Management of Pancreatic Neuroendocrine Tumors. Surg Oncol Clin N Am 2016;25:401-21.

10. Okabayashi T, Shima Y, Sumiyoshi T, et al. Diagnosis and management of insulinoma. World J Gastroenterol 2013;19:829-37.

11. Scott A, Hinwood D, Donnelly R. Radio-frequency ablation for symptom control in a patient with metastatic pancreatic insulinoma. Clin Endocrinol (Oxf) 2002;56:557-9.

12. Jürgensen C, Schuppan D, Neser F, et al. EUS-guided alcohol ablation of an insulinoma. Gastrointest Endosc 2006;63:1059-62.

13. Deprez PH, Claessens A, Borbath I, et al. Successful endoscopic ultrasound-guided ethanol ablation of a sporadic insulinoma. Acta Gastroenterol Belg 2008;71:333-7.

14. Limmer S, Huppert PE, Juette V, et al. Radiofrequency ablation of solitary pancreatic insulinoma in a patient with episodes of severe hypoglycemia. Eur J Gastroenterol Hepatol 2009;21:1097-101.

15. Akhlaghpoor S, Dahi F, Alinaghizadeh M, et al. CT fluoroscopy-guided transcaval radiofrequency ablation of insulinoma. J Vasc Interv Radiol 2011;22:409-10.

16. Vleggaar FP, Bij de Vaate EA, Valk GD, et al. Endoscopic ultrasound-guided ethanol ablation of a symptomatic sporadic insulinoma. Endoscopy 2011;43 Suppl 2 UCTN:E328-9.

17. Levy MJ, Thompson GB, Topazian MD, et al. US-guided ethanol ablation of insulinomas: a new treatment option. Gastrointest Endosc 2012;75:200-6.

18. Schnack C, Hansen CO, Beck-Nielsen H, et al. Treatment of insulinomas with alcoholic ablation. Ugeskr Laeger 2012;174:501-2.

19. Procházka V, Hlavsa J, Andrasina T, et al. Laparoscopic radiofrequency ablation of functioning pancreatic insulinoma: video case report. Surg Laparosc Endosc Percutan Tech 2012;22:e312-5.

20. Lee MJ, Jung CH, Jang JE, et al. Successful endoscopic ultrasound-guided ethanol ablation of multiple insulinomas accompanied with multiple endocrine neoplasia type 1 . Intern Med J 2013;43:948-50.

21. Bor R, Farkas K, Balint A, et al. Endoscopic ultrasoundguided ethanol ablation: an alternative option for the treatment of pancreatic insulinoma. Orv Hetil 2014;155:1647-51.

22. Rossi S, Viera FT, Ghittoni G, et al. Radiofrequency ablation of pancreatic neuroendocrine tumors: a pilot study of feasibility, efficacy, and safety. Pancreas 2014;43:938-45.

23. Qin SY, Lu XP, Jiang HX. EUS-guided ethanol ablation of insulinomas: case series and literature review. Medicine (Baltimore) 2014;93:e85.

24. Chen OT, Dojki FK, Weber SM, et al. Percutaneous Microwave Ablation of an Insulinoma in a Patient with Refractory Symptomatic Hypoglycemia. J Gastrointest Surg 2015;19:1378-81.

25. Lakhtakia S, Ramchandani M, Galasso D, et al. EUSguided radiofrequency ablation for management of pancreatic insulinoma by using a novel needle electrode (with videos). Gastrointest Endosc 2016;83:234-9.

26. Yang D, Inabnet WB 3rd, Sarpel U, et al. EUS-guided ethanol ablation of symptomatic pancreatic insulinomas. Gastrointest Endosc 2015;82:1127. 
27. Paik WH, Seo DW, Dhir V, et al. Safety and Efficacy of EUS-Guided Ethanol Ablation for Treating Small Solid Pancreatic Neoplasm. Medicine (Baltimore) 2016;95:e2538.

28. Trikudanathan G, Mallery SJ, Amateau SK. Successful Endoscopic Ultrasound-Guided Alcohol Ablation of Sporadic Insulinoma Using Three-Dimensional Targeting (with Video). Clin Endosc 2016;49:399-401.

29. Waung JA, Todd JF, Keane MG, et al. Successful management of a sporadic pancreatic insulinoma by endoscopic ultrasound-guided radiofrequency ablation. Endoscopy 2016;48 Suppl 1:E144-5.

30. Bas-Cutrina F, Bargallo D, Gornals JB. Small pancreatic insulinoma: Successful endoscopic ultrasound-guided radiofrequency ablation in a single session using a 22-G fine needle. Dig Endosc 2017;29:636-8.

31. Burghardt K, Kaemmerer D, Michael A, et al. Successful endoscopic ultrasound-guided ethanol ablation of a symptomatic sporadic insulinoma in a patient with severe comorbidities not suitable for pancreatic surgery. Diabetes Metab 2018;44:84-6.

32. Dąbkowski K, Gajewska P, Walter K, et al. Successful

Cite this article as: Egorov AV, Vasilyev IA, Musayev GH, Mironova AV. The role of microwave ablation in management of functioning pancreatic neuroendocrine tumors. Gland Surg 2019;8(6):766-772. doi: 10.21037/gs.2019.12.07
EUS-guided ethanol ablation of insulinoma, four-year follow-up. Case report and literature review. Endokrynol Pol 2017;68:472-9.

33. Luo Y, Li J, Yang A, et al. 68Ga-Exendin-4 PET/CT in Evaluation of Endoscopic Ultrasound-Guided Ethanol Ablation of an Insulinoma. Clin Nucl Med 2017;42:310-1.

34. Mittal M, Yip B, Lee JG. Endoscopic Ultrasound-Guided Ethanol Ablation for Control of Local-Regional Metastatic Insulinoma. Pancreas 2017;46:e17.

35. de Sousa Lages A, Paiva I, Oliveira P, et al. Endoscopic ultrasound-guided ethanol ablation therapy for pancreatic insulinoma: an unusual strategy. Endocrinol Diabetes Metab Case Rep 2017;2017. doi: 10.1530/EDM-16-0145.

36. Facciorusso A, Serviddio G, Muscatiello N. Local ablative treatments for hepatocellular carcinoma: An updated review. World J Gastrointest Pharmacol Ther 2016;7:477-89.

37. Koshy AA, Gordon IO, Van Ha TG, et al. Metastatic Insulinoma Following Resection of Nonsecreting Pancreatic Islet Cell Tumor: A Case Report and Review of the Literature. J Investig Med High Impact Case Rep 2013;1:2324709612473274. 